\title{
Cyclooxygenase-2-Dependent Bronchoconstriction in Perfused Rat Lungs Exposed to Endotoxin
}

\author{
Stefan Uhlig,* Rolf Nüsing, ${ }^{\dagger}$ Alexander von Bethmann,* \\ Roland Lewis Featherstone,* Thomas Klein,* Frank Brasch, ${ }^{*}$ \\ Klaus-Michael Müller, ${ }^{\neq}$Volker Ullrich,* and Albrecht Wendel* \\ *Faculty of Biology, University of Konstanz, Konstanz, Germany \\ ${ }^{\dagger}$ Medical Center of Pediatrics, University Hospital Marburg, Marburg, \\ Germany \\ †Professional Associations' Hospital "Bergmannsheil" University \\ Hospital, Institute of Pathology, Bochum, Germany
}

\begin{abstract}
Background: Lipopolysaccharides (LPS), widely used to study the mechanisms of gram-negative sepsis, increase airway resistance by constriction of terminal bronchioles. The role of the cyclooxygenase (COX) isoenzymes and their prostanoid metabolites in this process was studied. Materials and Methods: Pulmonary resistance, the release of thromboxane (TX) and the expression of COX-2 mRNA were measured in isolated blood-free perfused rat lungs exposed to LPS.

Results: LPS induced the release of TX and caused increased airway resistance after about $30 \mathrm{~min}$. Both TX formation and LPS-induced bronchoconstriction were prevented by treatment with the unspecific COX inhibitor acetyl salicylic acid, the specific COX-2 inhibitor CGP-28238, dexamethasone, actinomycin D, or cycloheximide. LPS-induced bronchoconstriction was also in-
\end{abstract}

hibited by the TX receptor antagonist BM-13177. The TX-mimetic compound, U-46619, increased airway resistance predominantly by constricting terminal bronchioles. COX-2-specific mRNA in lung tissue was elevated after LPS exposure, and this increase was attenuated by addition of dexamethasone or of actinomycin D. In contrast to LPS, platelet-activating factor (PAF) induced immediate TX release and bronchoconstriction that was prevented by acetyl salicylic acid, but not by CGP-28238. Conclusions: LPS elicits the following biochemical and functional changes in rat lungs: (i) induction of COX-2; (ii) formation of prostaglandins and TX; (iii) activation of the TX receptor on airway smooth muscle cells; (iv) constriction of terminal bronchioles; and (v) increased airway resistance. In contrast to LPS, the PAF-induced TX release is likely to depend on COX-1.

\section{INTRODUCTION}

The adult respiratory distress syndrome is a part of the systemic inflammatory response syndrome frequently associated with the systemic presence of lipopolysaccharides (LPS). It is characterized by perturbations in gas exchange, edema formation, pulmonary hypertension, and increased airway resistance (1). Experimental exposure to LPS has thus been used to study the mechanistic aspects of these syndromes. Using the isolated

Address correspondence and reprint requests to: Stefan Uhlig, Biochemical Pharmacology, University of Konstanz, P.O.B. 5560 M668, D-78434 Konstanz, Germany. and blood-free perfused rat lung, we have recently shown that $30 \mathrm{~min}$ after perfusion with LPS, airway resistance starts to increase as a result of constriction of terminal bronchioles (2). A similar time course of bronchoconstriction is seen after intravenous injection of LPS in sheep (3) or pigs (4). This effect was attributed to thromboxane (TX) which appeared in the blood of the animals in parallel to the bronchoconstriction, about 30 min after injection of LPS $(3,5)$. The enzymatic mechanisms involved in this early phase are largely unknown.

The existence of two different cyclooxygenase $(\mathrm{COX})$ isoenzymes is a recent discovery. 
While COX-1 is constitutively expressed, COX-2 activity is induced by inflammatory stimuli such as LPS or cytokines (6). It has been shown in vitro that LPS induces COX-2 in alveolar macrophages (AM) $(7,8)$, in pulmonary epithelial cells (9) and in rat lung tissue (10). However, in these cellular studies it was not possible to assess the functional consequences of enzyme induction.

The time lag between injection of LPS and formation of TX might be due to the time required for COX-2 induction; we tested this hypothesis in functionally intact whole organ system, i.e., the isolated perfused rat lung using isolated blood-free rat lungs. LPS-induced bronchoconstriction in this sytem was compared with platelet activating factor (PAF)-induced bronchoconstriction.

\section{MATERIAL AND METHODS}

\section{Animals and Chemicals}

Lungs weighing 220-250 g from female Wistar rats (Zentralinstitut Hannover, Germany) were used. Pentobarbital sodium was from the Wirtschaftgenossenschaft Deutscher Tierärzte (Hannover, Germany). Lipopolysaccharide Salmonella minnesota, dexamethasone (water soluble), PAF ( $\mathrm{L}-\alpha$-phosphatidylcholine, $\beta$-acetyl- $\gamma$-O-[octadec-9-cis-enyl]), cycloheximide, actinomycin $\mathrm{D}$, and heparin were from Sigma (Deisenhofen, Germany); Hepes and glucose from Boehringer Mannheim (Mannheim, Germany); U-46619 (9,11-dideoxy-9 $\alpha$, $11 \alpha$-epoxymethanoprostaglandin F2 $\alpha$ ) from Paesel (Frankfurt, Germany); CGP-28238 (6-[2,4-difluorophenoxy]-5-methyl-sulfonylamino-1-indanone) was a gift from Dr. Wiesenberg-Boettcher (CibaGeigy, Basel, Switzerland). BM-13177 ([4-[2(phenylsulfonyl)amino]ethyl]phenoxyacetic acid) from Dr. Stegmeier (Boehringer Mannheim); WEB-2086 (3-[4-(2-chlorophenyl)-9-methyl-6Hthieno[3,2-f] [1, 2, 4] triazolo-[4, 3-a][1, 4]-diazepin-2-yl]-1-(4morpholinyl)-1-propanon from Dr. Heuer (Boehringer Ingelheim, Ingelheim, Germany); AA-861 (2,3,5-trimethyl-6-(12-hydroxy-5, 10-dodecadiynyl)-1,4-benzochinone from Takeda Chemical Industries (Osaka, Japan); MK-571 (3-(3(2 - (7 - chloro - 2 - quinolinyl)ethenyl)phenyl)((3 -dimethylamino - 3 -oxopropyl)thio)methyl) - propanoic acid) from Dr. Ford-Hutchinson (Merck-Frosst, Quebec, Canada).

\section{Perfusion System}

Rat lungs suspended by the trachea were perfused at constant hydrostatic pressure through the pulmonary artery, with a total volume of 100 $\mathrm{ml}$ of recirculating Krebs-Henseleit buffer that contained $2 \%$ albumin, $0.1 \%$ glucose, and $0.3 \%$ HEPES as previously described (11). They were ventilated by negative pressure (humidified air, 80 breaths $/ \mathrm{min}$, tidal volume $1.6-2 \mathrm{ml}$, deep breath of $-16 \mathrm{~cm} \mathrm{H}_{2} \mathrm{O}$ every $5 \mathrm{~min}$ ). Artificial thorax chamber pressure was measured with a differential pressure transducer (Validyne DP4514), and air flow velocity with a pneumotachograph tube (Fleisch Type 0000) connected to a differential pressure transducer (Validyne DP 4515). The perfusate flow (Narcomatic RT 500) as well as the $\mathrm{pH}$ of the buffer before and after passage through the lung were continuously monitored. The $\mathrm{pH}$ of the perfusate before entering the lung was kept at 7.35 by automatic bubbling of the buffer with $\mathrm{CO}_{2}$. Lungs were always perfused with buffer for $40 \mathrm{~min}$ in order to obtain a baseline before infusion of LPS (dissolved in $1 \mathrm{ml}$ phosphate-buffered saline [PBS], $0.005 \%$ hydroxylamine). Acetyl salicylic acid was dissolved in $1 \mathrm{ml}$ of $\mathrm{PBS} / \mathrm{NaHCO}_{3}, \mathrm{BM}-13177$, and CGP28238 in $10 \mu \mathrm{l}$ or $2 \mu \mathrm{l}$ DMSO, respectively. Up to $50 \mu \mathrm{l}$ of DMSO alone did not affect the LPS-induced bronchoconstriction.

Data were transmitted to a computer (Compaq Deskpro 286) via an A/D-converter (Metrabyte 16) or a RS232 serial interface and analyzed by a propriety program (language: ASYST 3.1). In addition, chamber pressure, tidal volume (by integration), and perfusate flow were recorded on a Graphtec WR 3310. Parameters describing lung mechanics were analyzed by: $P=1 / C V+$ $R_{\mathrm{L}} d V / d t$, where $P$ is chamber pressure, $C$ pulmonary compliance, $V$ tidal volume, and $R_{\mathrm{L}}$ pulmonary resistance. Data presentation in this article is focused on bronchoconstriction as the major effect of perfusion of rat lungs with LPS (2).

\section{Reverse Transcription-Polymerase Chain Reaction Analysis}

Lungs were lavaged with cold $\left(4^{\circ} \mathrm{C}\right)$ PBS/EDTA $(1 \%)$ and alveolar macrophages were prepared by centrifugation at $400 \times g$. Such preparations contained over $95 \%$ alveolar macrophages. Lavaged tissue was cut into pieces of about $10 \mathrm{mg}$ and stored together with macrophages at $-80^{\circ} \mathrm{C}$. RNA was isolated by a using Chaosolv solution (Biotecx, suppliers' manual). Four micrograms RNA were used for target-specific reverse transcription (RT) with Superscript reverse transcriptase and specific primers (GC content of 50$60 \%)$. 
The wobble primer PCOXRl $\left(5^{\prime}-\mathrm{A}(\mathrm{G} / \mathrm{C}) \mathrm{A}\right.$ GCTCAGT(G/T)GA(A/G)CG(C/T)CT)-3') complementary to an homologous $3^{\prime}$ part of cyclooxygenase- 1 and - 2 was used for simultaneous RT of the mRNA of both cyclooxygenases. For TX synthase the primer was PTXSMR1 (5'-GCGTGA CACAATCTTGATGTAGACTCC- $3^{\prime}$ ) and for $\beta$-actin BAHR 1 (5'-CTAGAAGCATTTGCGGTGGAC $\left.3^{\prime}\right)$. After removal of excess primers polymerase chain reaction (PCR) amplification was performed using the cDNA template with the following nested primer pairs: for cyclooxygenase- 1 PCOX1MR2 (5'-ACCCGTCATCTCCAGGGTAA $\left.3^{\prime}\right)$ and PCOX1Fl (5'-CAGCCCTTCAATGA(A/G) TACCG-3'), for cyclooxygenase-2 PCOX2MR2 (5'-ATCTAGTCTGGAGTGGGAGG-3') and PCO X2F1 (5'-AATGAGTACCGCAAACGCTT-3'), for TX synthase PTXSRR2 (5'-CTAGCTGAAGTG GAACCTGAG-3') and PTXSRF1 (5'-TGAGTGC CAGGAGAGGCTTCT- $3^{\prime}$ ) and for $\boldsymbol{\beta}$-actin BAHR 1 and BAHF1 $\left(5^{\prime}\right.$-CATCACCATTGGCAATGAGCG $\left.3^{\prime}\right)$. The reactions were cycled 32 times ( $30 \mathrm{sec}$ at $94^{\circ} \mathrm{C}, 30 \mathrm{sec}$ at $56^{\circ} \mathrm{C}$, and $30 \mathrm{sec}$ at $72^{\circ} \mathrm{C}$ after a 5 -min denaturing step at $95^{\circ} \mathrm{C}$ ). Products were analyzed by $2 \%$ agarose gel electrophoresis and ethidium bromide staining. Without specific primer or with the PCR reaction lacking the template, no amplification products were found. Samples were assayed in various dilutions to ensure proportionality in the yield of PCR products. The identity of the fragments was evaluated by their molecular mass and restriction enzyme analysis.

\section{Measurement of TX}

In samples from the perfusate stored at $-20^{\circ} \mathrm{C}$ $\mathrm{TXA}_{2}$ was assessed as the stable metabolite $\mathrm{TXB}_{2}$ by EIA (Cayman, Ann Arbor, MI U.S.A.). The cross-reactivity of the detecting antibody was $\mathrm{TXB}_{2} 100 \%$, 2,3-dinor $\mathrm{TXB}_{2} 8.2 \%$, prostaglandins (e.g., $\mathrm{PGD}_{2}, \mathrm{PGE}_{2}$, 6-keto $\mathrm{PGF}_{1 \alpha}$ ) $<0.5 \%$. Prostacyclin was assessed as the stable metabolite 6-keto PGF P $_{1 \alpha}$ by EIA (Cayman). The cross-reactivity of the detecting antibody was $100 \%$ for 6-keto PGF ${ }_{1 \alpha^{\prime}} 8.7 \%$ for 2,3-dinor-6-keto PGF $1 \alpha^{\prime}$ $2.1 \%$ for $\mathrm{PGF}_{2 \alpha}, 0.92 \%$ for $\mathrm{PGE}_{2}, 0.8 \%$ for $\mathrm{PGF}_{1 \alpha^{\prime}}$ and $\leq 0.1 \%$ for other prostaglandins. Recovery of TX as well as prostacyclin was $>95 \%$.

\section{Scanning Electron Microscopy}

Ten minutes after treatment with $50 \mathrm{nM}$ U46619, lungs were fixed by perfusing the pulmonary artery with $1.5 \%$ glutaraldehyde/ $1.5 \%$ paraformaldehyde in $0.2 \mathrm{M}$ HEPES buffer ( $\mathrm{pH}$ 7.4) at a hydrostatic pressure of $13 \mathrm{~cm} \mathrm{H}_{2} \mathrm{O}$. The lungs were stored in cold fixative for $24 \mathrm{hr}$. Following fixation and sampling, specimens were rinsed in $0.2 \mathrm{M}$ phosphate buffer. After dehydration through a graded series of ethanol and subsequent critical-point drying, coating with carbon was performed using a sputter coater (Edwards, Crawley, West Sussex, Great Britain). Tissue samples were examined with a DSM 940 (Zeiss, Oberkochen, Germany).

\section{Statistics}

Data in the figures are given as mean \pm SEM, while data in the tables and the text are given as mean \pm SD. Data were analyzed by analysis of variance (ANOVA), and in case of differences among the groups, Dunnett's test was performed to test which group was different from the respective control group (SAS software, release 6.08, SAS Institute Inc., Cary, NC, U.S.A.). $p<$ 0.05 was considered to be significant.

\section{RESULTS}

\section{Bronchoconstriction in the Isolated Perfused Rat Lung}

Isolated rat lungs were perfused with $50 \mu \mathrm{g} / \mathrm{ml}$ LPS, a concentration found in the blood of rats that received a shock dose $(15 \mathrm{mg} / \mathrm{kg})$ of LPS (12). This treatment caused increased airway resistance, as well as decreased pulmonary compliance and tidal volume (Table 1), starting about 30 min after infusion of LPS (Fig. 1). Under these conditions, LPS did not affect vascular resistance or lung weight (2). As reported previously (11), physiological parameters of vehicle-perfused lungs did not change significantly during the time of perfusion (data not shown).

\section{Role of Lipoxygenase Products and PAF}

Since PAF and arachidonic acid-derived metabolites of lipoxygenases have been implicated in mediating the pulmonary alterations induced by LPS $(13,14)$, we tested their role in our system. Table 1 shows that neither inhibition of 5-lipoxygenase with AA-861, $\mathrm{LTC}_{4} / \mathrm{D}_{4}$ receptor antagonism with MK-571 (15), nor PAF-receptor antagonism with WEB-2086 prevented the LPSinduced increase in airway resistance. AA-861 and WEB-2086 were used at doses previously 
TABLE 1. Effects of various inhibitors on LPS-induced bronchoconstriction in perfused rat lung

\begin{tabular}{lccccc}
\hline Pretreatment & LPS & $\boldsymbol{n}$ & $\boldsymbol{T V}(\mathbf{m l})$ & $\begin{array}{c}\boldsymbol{C}_{\mathbf{L}} \\
\left(\mathbf{m l} / \mathbf{c m} \mathbf{H}_{\mathbf{2}} \mathbf{O}\right)\end{array}$ & $\begin{array}{c}\boldsymbol{R}_{\mathbf{L}} \\
\left(\mathbf{c m} \mathbf{H}_{\mathbf{2}} \mathbf{O} \cdot \mathbf{s e c} / \mathbf{m l}\right)\end{array}$ \\
\hline- & - & 19 & $1.38 \pm 0.23$ & $0.16 \pm 0.04$ & $0.30 \pm 0.04$ \\
WEB-2086 & LPS & 24 & $0.44 \pm 0.17^{a}$ & $0.05 \pm 0.02^{a}$ & $0.65 \pm 0.26^{a}$ \\
MK-571 & LPS & 4 & $0.34 \pm 0.11^{a}$ & $0.04 \pm 0.03^{a}$ & $0.66 \pm 0.29^{a}$ \\
AA-861 & LPS & 3 & $0.39 \pm 0.08^{a}$ & $0.03 \pm 0.03^{a}$ & $0.83 \pm 0.23^{a}$ \\
BM-13177 & LPS & 5 & $0.35 \pm 0.12^{a}$ & $0.05 \pm 0.01^{a}$ & $0.56 \pm 0.30^{a}$ \\
ASA & LPS & 6 & $1.17 \pm 0.33$ & $0.16 \pm 0.07$ & $0.32 \pm 0.05$ \\
CGP-28238 & LPS & 4 & $1.36 \pm 0.39$ & $0.18 \pm 0.07$ & $0.31 \pm 0.04$ \\
Dexamethasone & LPS & 3 & $1.16 \pm 0.29$ & $0.24 \pm 0.05$ & $0.27 \pm 0.04$ \\
& LPS & 3 & $1.57 \pm 0.56$ & $0.26 \pm 0.10$ & $0.25 \pm 0.03$ \\
\hline
\end{tabular}

Tidal volume $(T V)$, pulmonary compliance $\left(C_{\mathrm{L}}\right)$ and pulmonary resistance $\left(R_{\mathrm{L}}\right) 110$ min after addition of vehicle, LPS or LPS plus various inhibitors. Ten minutes prior to injection of LPS $(50 \mu \mathrm{g} / \mathrm{ml})$, lungs were pretreated with the PAF-receptor antagonist WEB-2086 $(66 \mu \mathrm{M})$, the leukotriene receptor antagonist MK-571 $(10 \mu \mathrm{M})$, the 5-lipoxygenase inhibitor AA-861 (10 $\mu \mathrm{M})$, the TX receptor antagonist BM-13177 $(20 \mu \mathrm{M})$, the unspecific cyclooxygenase inhibitor acetyl salicylic acid (ASA, $275 \mu \mathrm{M})$ or the specific cyclooxygenase-2 inhibitor CGP-28238 $(1 \mu \mathrm{M})$. Dexamethasone $(10 \mu \mathrm{M})$ was administered 30 min before injection of LPS. Data are expressed as means $\pm \mathrm{SD}$.

${ }^{a} p<0.05$ against control.

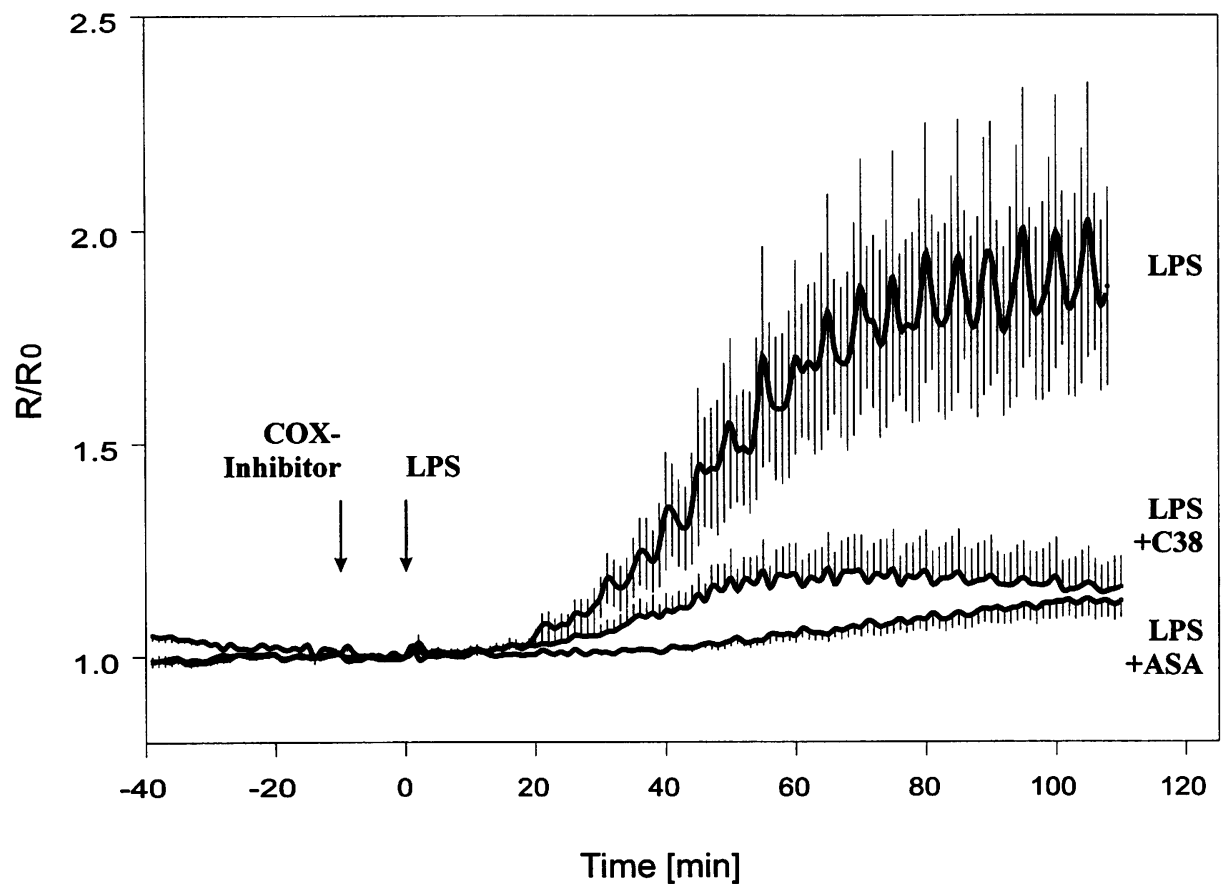

FIG. 1. Time course of LPS-induced bronchoconstriction $(n=6)$ and its prevention by pretreatment with the unspecific cyclooxygenase inhibitor acetyl salicylic acid (ASA, $275 \mu M ; n=4)$ or the specific cyclooxygenase-2 inhibitor CGP28238 (C38, $1 \mu \mathrm{M} ; n=3) 10 \mathrm{~min}$ before injection of LPS (50 $\mu \mathrm{g} / \mathrm{ml})$ Data are expressed as means $\pm S E M$. R/R $R_{0}$, resistance normalized to time point 0 . 

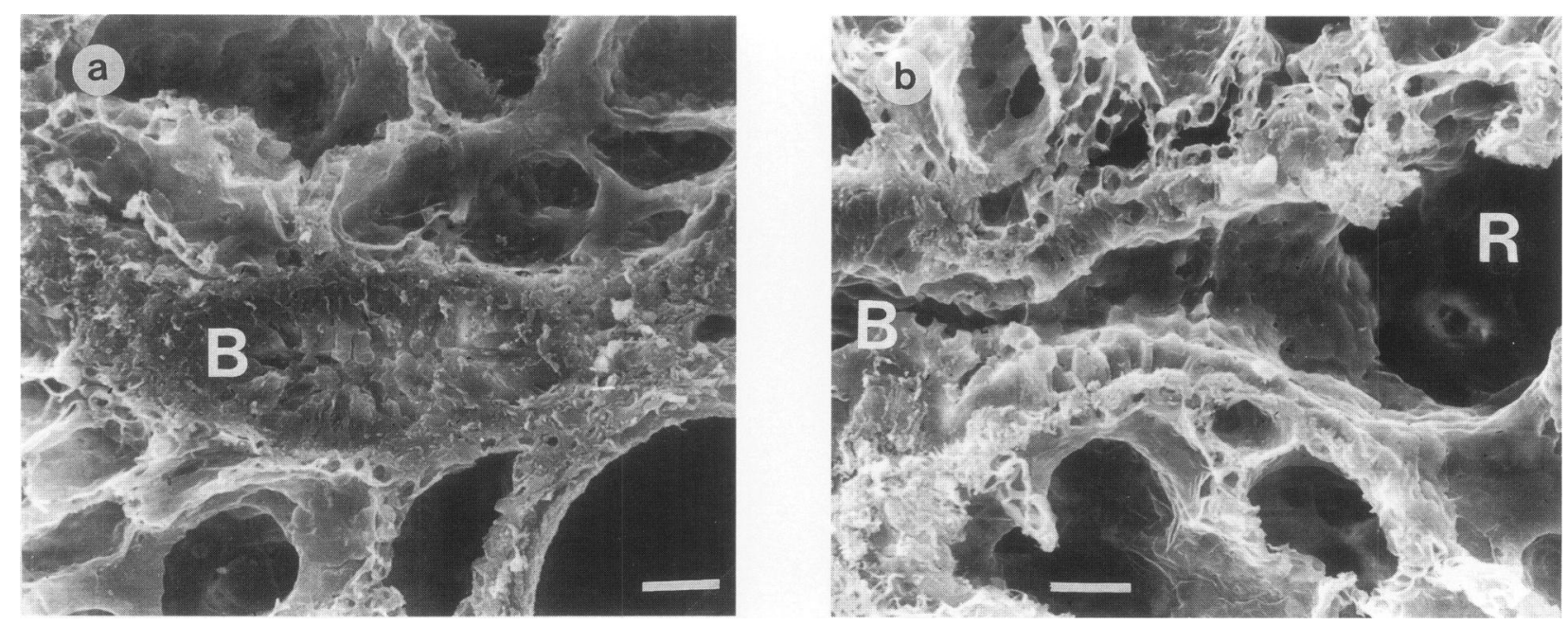

FIG. 2. Scanning electron microscopic image of isolated rat lungs perfused with the TX mimetic U46619 (50 nM)

(a) Cross section of completely occluded small bronchiole (B). (b) Longitudinal section of the bronchial-alveolar duct junction showing a constricted terminal bronchiole just before transition into the respiratory bronchiole. Bars $=20 \mu \mathrm{m}$; final magnification: $500 \times$.

shown to be effective in the rat lung (16). At the dose used, MK-571 prevented the increased pulmonary resistance induced by $160 \mathrm{nmol} \mathrm{LTC}_{4}$ (data not shown). In addition, relatively unspecific inhibitors of 5-lipoxygenase such as $10 \mu \mathrm{M}$ ebselen, $100 \mu \mathrm{M}$ nordihydroguaiaretic acid, or $640 \mu \mathrm{M}$ diethylcarbamazine did not attenuate LPS-induced bronchoconstriction in our model (data not shown). These findings suggest a minor role of PAF or leukotriene metabolites in inducing or propagating lung failure following endotoxin challenge in our model.

\section{Role of TX}

Bronchoconstriction induced by LPS in various animal models has been attributed to TX $(3,5,17)$. Pretreatment of the lungs with the TX receptor antagonist $\mathrm{BM}-13177$ prevented the LPS-induced increase in pulmonary resistance (Table 1). Likewise, unspecific inhibition of cyclooxygenase with acetyl salicylic acid provided protection similar to BM-13177 (Fig. 1, Table 1). Thus, these and published data suggest that formation of TX was responsible for the observed bronchoconstriction. Since we have previously reported that bronchoconstriction evoked by LPS in the perfused rat lung occurred at the terminal bronchioles (2), we localized the anatomical site of the suspected TX action by using the stable TX mimetic U-46619. Perfusion with $50 \mathrm{nM}$
U-46619 increased pulmonary and vascular resistance almost instantly. Vasoconstriction appeared to occur primarily at the arterioles (not shown). Bronchoconstriction affected predominantly the terminal bronchioles, whereas all of the larger airways appeared open (Fig. 2).

\section{Role of Cyclooxygenase 2}

Since bronchoconstriction initiated by LPS needed $30 \mathrm{~min}$ to start, we investigated the hypothesis that this period is required for induction of cyclooxygenase-2. Pretreatment of lungs with the specific COX-2 inhibitor CGP-28238 (18) provided protection against the LPS-induced increase in pulmonary resistance (Fig. 1, Table 1). Since it is known that steroids prevent the LPSinduced induction of COX-2 mRNA (19), we perfused lungs with dexamethasone $30 \mathrm{~min}$ prior to LPS. After such pretreatment, the LPSinduced bronchoconstriction was almost completely abrogated (Table 1).

Following perfusion with LPS, synchronous with the time course of bronchoconstriction, the perfusate levels of the stable metabolite of $\mathrm{TXA}_{2}$ (i.e., $\mathrm{TXB}_{2}$ ) started to increase (Fig. 3). Pretreatment with the COX-2-specific inhibitor CGP28238 or dexamethasone almost completely prevented this response (Fig. 3A). Similar observations were made for prostacyclin assayed as its stable metabolite 6-keto-PGF ${ }_{1 \alpha}$ (Fig. 3B). 

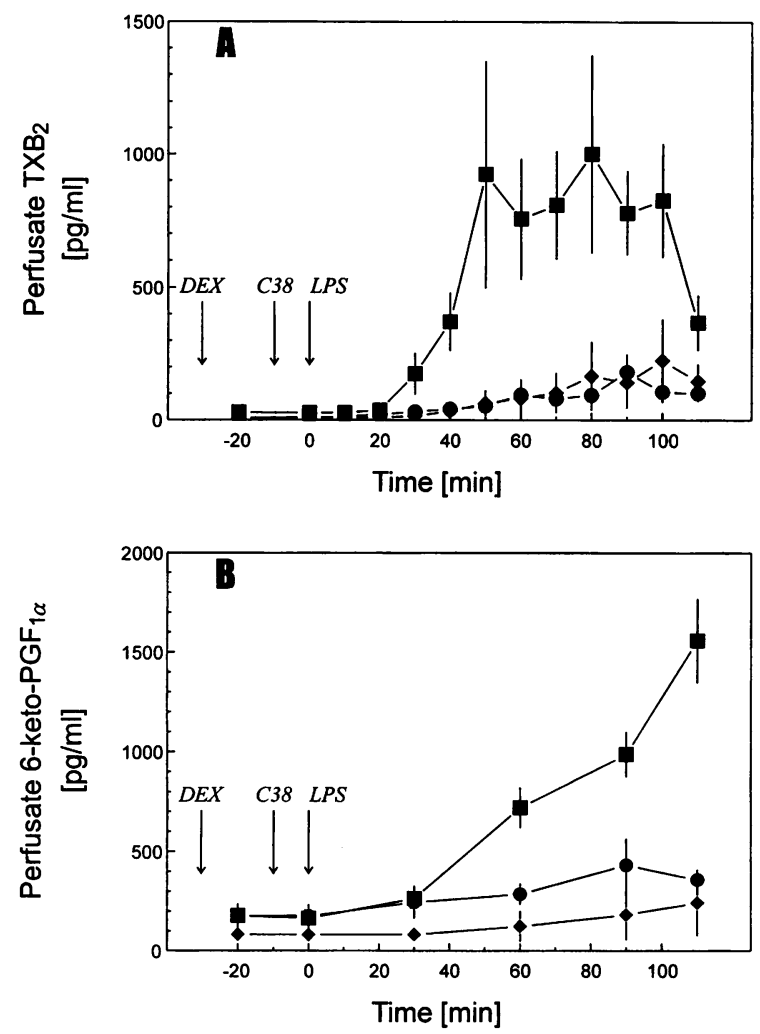

FIG. 3. Time course of LPS-induced release of $\mathrm{TXB}_{2}$ (A) and 6-keto-PGF ${ }_{1 \alpha}$ (B) into the perfusate (ש)

Lungs were pretreated with the cyclooxygenase-2 inhibitor CGP28238 $(\bullet, 1 \mu \mathrm{M})$ or with dexamethasone $(\diamond, 10 \mu \mathrm{M}) 10$ or $30 \mathrm{~min}$ before injection of LPS $(50 \mu \mathrm{g} / \mathrm{ml})$, respectively. Data are expressed as means \pm SEM.

After exposure to LPS for $60 \mathrm{~min}$, COX-2specific mRNA content was increased in lung tissue and in alveolar macrophages obtained from LPS-treated lungs compared with control lungs (Fig. 4). The amounts of mRNA specific for COX-1 and TX synthase in these cells were not enhanced by LPS treatment (Fig. 4). Accounting for the different dilutions (see legend of Fig. 4), it appears that lung tissue and alveolar macrophages contain similar amounts of mRNAs for COX- 1 and $\beta$-actin, whereas COX- 2 prevails in lung tissue and TX synthase in alveolar macrophages. In tissue from dexamethasone-pretreated lungs, no elevation of COX-2-specific RNA was found (Fig. 4).

Inhibition of transcription with actinomycin D or of translation with cycloheximide completely prevented the LPS-induced bronchoconstriction and TX formation (Fig. 5). With respect to mRNA expression, we found that pretreatment with actinomycin $\mathrm{D}$ reduced the amounts of COX-2-specific RNA, whereas cycloheximide caused a small increase (Fig. 6).

\section{PAF-Induced Bronchoconstriction}

We next investigated the specificity of the COX-2 inhibitor CGP-28238 in our system. As an approach, we used the PAF-induced pressor response (i.e., vaso- and bronchoconstriction) which is largely mediated by TX (16). In this model, within 2 min after bolus injection of 5 nmol PAF, pulmonary resistance increased and TX was released into the perfusate (Fig. 7). Acetyl salicylic acid largely prevented the PAFinduced pressor response and TX release (Fig. 7). Since in untreated lungs COX-2 mRNA levels were low (Fig. 4) and since induction of COX-2 activity is highly unlikely to occur within $2 \mathrm{~min}$, we hypothesized that the COX-2 inhibitor CGP23838 should not prevent PAF-induced pressor responses. Figure 7A shows that in contrast to pretreatment with acetyl salicylic acid, CGP-28238 indeed failed to prevent the PAFinduced bronchoconstriction at concentrations that exceeded those effective against LPS. The COX-2 inhibitor also failed to attenuate the PAFinduced TX release (Fig. 7B) and $30 \mathrm{~min}$ after injection of PAF, no increase in COX-2-specific mRNA was observed under these conditions (data not shown).

\section{DISCUSSION}

Bronchoconstriction is a major complication in both acute and chronic human lung diseases. For the reasons given below our results indicate that the following sequence of events is likely to occur in lungs exposed to endotoxin: (i) LPS causes induction of COX-2 in the lung; (ii) this newly expressed COX-2 enzyme converts arachidonic acid to $\mathrm{PGH}_{2}$, which is further metabolized to TX by constitutive TX synthase; (iii) the formed TX predominantly activates TX receptors located on peripheral airway smooth muscle cells; (iv) the resulting constriction of terminal bronchioles increases airway resistance.

\section{Evidence for Induction of COX-2}

The causal involvement of COX-2 via induction in LPS-induced lung injury in our model is based on four independent experimental findings: (i) 
LT

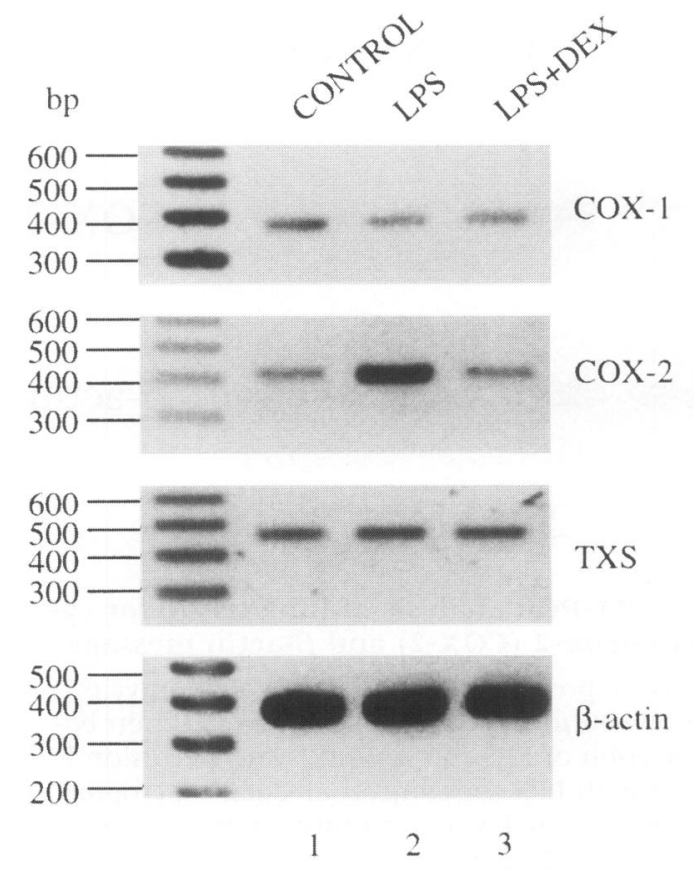

AM

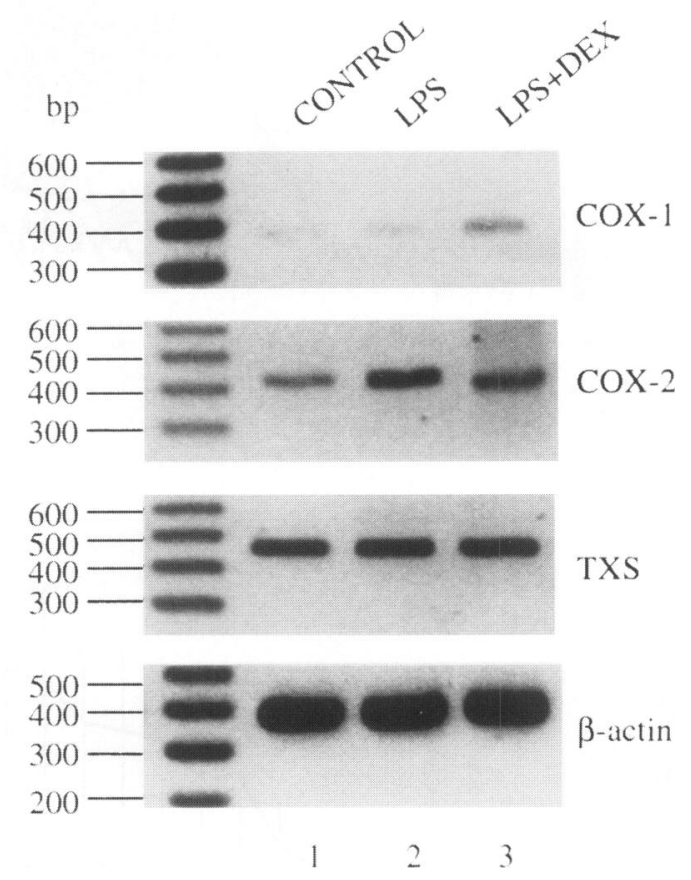

FIG. 4. RT-PCR analysis of lung tissue (LT) and alveolar macrophages (AM) obtained after perfusion with LPS for $60 \mathrm{~min}$

Shown are cyclooxygenase-1 (COX-1), cyclooxygenase-2 (COX-2), TX synthase (TXS), and $\beta$-actin message. Lungs were perfused with vehicle (control), $50 \mu \mathrm{g} / \mathrm{ml}$ LPS (LPS), or $10 \mu \mathrm{M}$ dexamethasone 30 min before injection of 50 $\mu \mathrm{g} / \mathrm{ml}$ LPS (LPS + Dex). The cDNA dilutions were as follows (lung tissue/alveolar macrophages): COX-1, 1:1/1:1; COX-2, 1:100/1:3; TX synthase, 1:10/1:20; $\beta$-actin, 1:500/1:500.

The COX-2 inhibitor CGP-28238 prevented LPSinduced bronchoconstriction and TX release. Its specificity was demonstrated in rat mesangial cells, where CGP-28238 was at least 1000 times more potent in inhibiting COX-2 compared with inhibition of COX-1 activity in platelets (18). In our study, CGP-28238 did not prevent the PAFinduced bronchoconstriction, a response that is most likely elicited via COX-1. Therefore, we believe that CGP-28238 differentiated between COX-1 and COX-2 in our system at the concentration used. (ii) COX-2-specific mRNA was raised in lung tissue and alveolar macrophages obtained from endotoxin-treated lungs. (iii) Dexamethasone prevented the formation of TX and the bronchoconstriction due to LPS, and in accordance with previous findings (19), it suppressed the expression of COX-2-specific mRNA. While we are aware of an inhibition of phospholipase $A_{2}$ as a further mechanism (20), these data provide substantial evidence that induction of
COX-2 is a prerequisite for LPS-induced bronchoconstriction. (iv) The increase in COX-2-specific mRNA expression after LPS was attenuated by inhibiting transcription with actinomycin $\mathrm{D}$, thus favoring an induction phenomenon rather than stabilization of mRNA.

\section{Evidence for TX-Mediated Bronchoconstriction}

Of all known cyclooxygenase metabolites, TX has attracted the most attention as an agent causing bronchoconstriction. As far as endotoxin exposure is concerned, we now have several lines of evidence that identify TX as the pivotal mediator of bronchoconstriction in the rat lung: (i) 5-lipoxygenase products and PAF can be excluded as being responsible for LPS-induced bronchoconstriction. (ii) LPS caused an increased release of $\mathrm{TXB}_{2}$ into the perfusate and this increase coincided with the rise in pulmonary resistance. The 

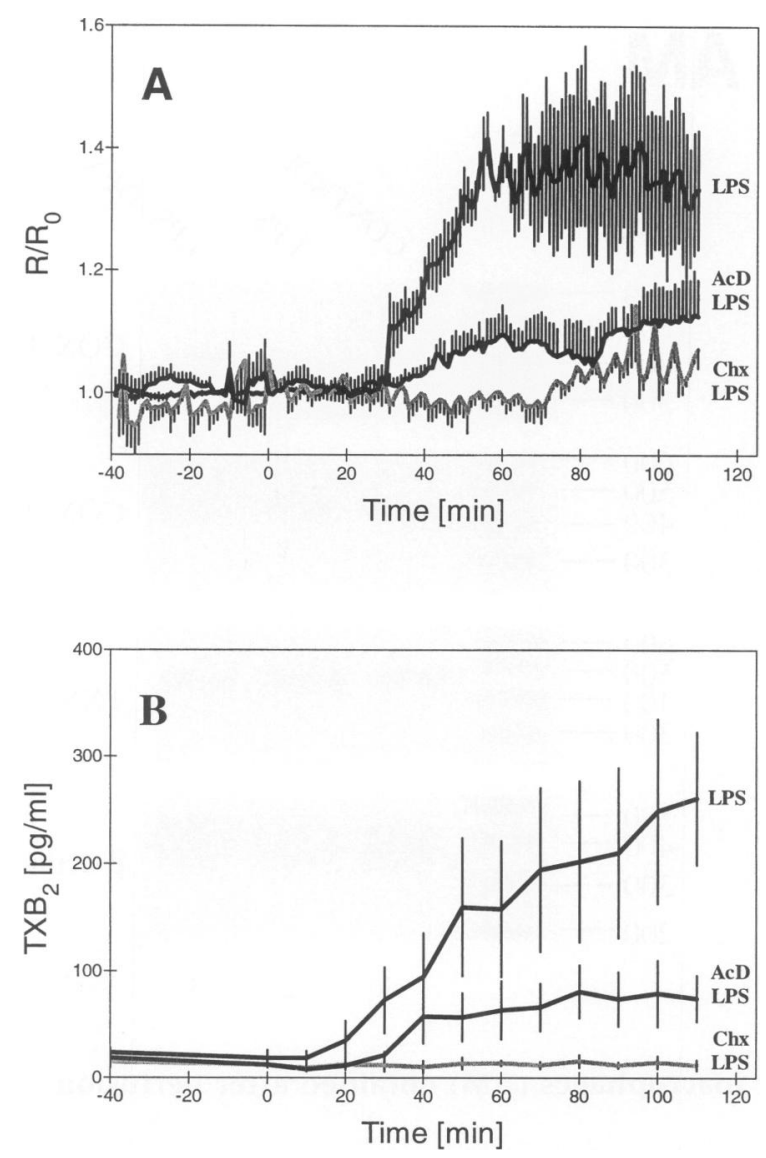

FIG. 5. Time course of LPS-induced bronchoconstriction (A) and TX release into the perfusate (B)

$10 \mathrm{~min}$ before injection of LPS $(50 \mu \mathrm{g} / \mathrm{ml})$, lungs were pretreated with either $0.3 \mu \mathrm{M}$ actinoymcin $\mathrm{D}$ (AcD) or with $100 \mu \mathrm{M}$ cycloheximide (Chx). Data are expressed as means $\pm \mathrm{SEM} ; n=3$. $\mathrm{R} / \mathrm{R}_{0}$, resistance normalized to time point 0 . Please note that in these experiments lungs from male Sprague-Dawley rats were used.

cellular source of TX in the isolated lung, however, remains unknown (see next section). In addition, the stable prostacyclin metabolite 6-keto-PGF ${ }_{1 \alpha}$ was also increased (for its significance see point $\mathrm{v}$ below). A similar time course of TX and prostacyclin formation after treatment with LPS has been reported in vivo in rats (21) and sheep (3). (iii) Inhibitors of the synthesis of TX (i.e., the COX inhibitors acetyl salicylic acid and CGP-28238) attenuated the LPS-induced bronchoconstriction. (iv) The TX receptor antagonist BM-13177 was protective against LPS in our model. (v) The stable TX receptor agonist U-46619 mimicked the effects induced by LPS

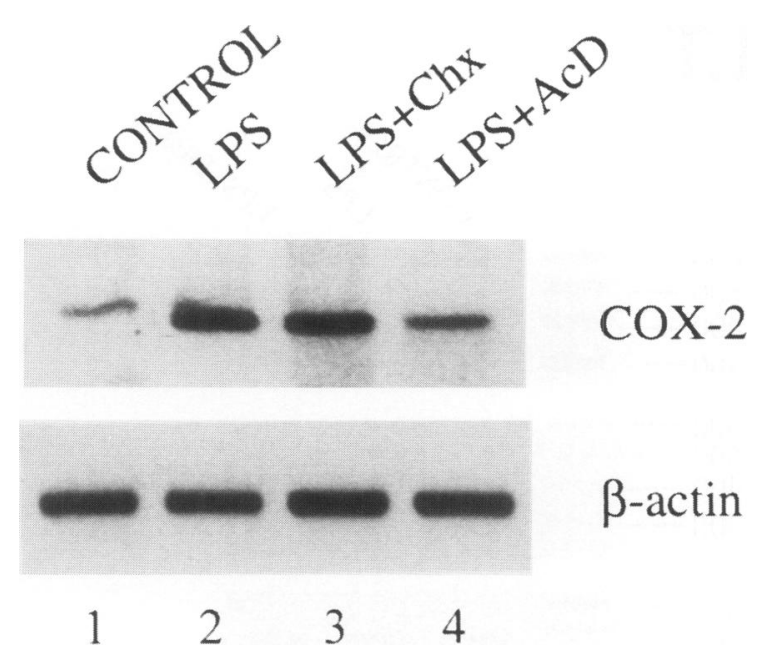

FIG. 6. RT-PCR analysis of lung tissue for cyclooxygenase-2 (COX-2) and $\beta$-actin message Lungs were pretreated with $0.3 \mu \mathrm{M}$ actinomycin D (AcD) or $100 \mu \mathrm{M}$ cycloheximide (Chx) $10 \mathrm{~min}$ before injection of LPS $(50 \mu \mathrm{g} / \mathrm{ml})$. After perfusion for 110 min with LPS (or control) alveolar macrophages were removed by lavage and lung tissue was analyzed for COX-2-specific mRNA. Please note that in these experiments lungs from male Sprague-Dawley rats were used.

and caused bronchoconstriction at the same anatomical site as observed for LPS (2) (i.e., the terminal bronchioles). In addition, however, U-46619 also caused constriction of arterioles which was not observed after infusion of LPS. We speculate that the absence of vasoconstriction after injection of LPS is due to the concomitant release of prostacyclin, which is a more potent vasodilator than bronchodilator. The preferential constriction of arterioles by U-46619 confirms previous data obtained by occlusion techniques in perfused rat lung (22).

(vi) Inhibiting translation by cycloheximide prevented both LPS-induced TX formation and bronchoconstriction, suggesting that de novo synthesis of COX-2 is required. In agreement with previous cellular studies, cycloheximide treatment enhanced rather than decreased amounts of COX-2 mRNA (23).

\section{The Source of TX}

Although it was shown that rat (24) as well as human lung (25) produce TX and that among the major organs, human lung contains the highest specific activity of TX synthase (25), the cel- 

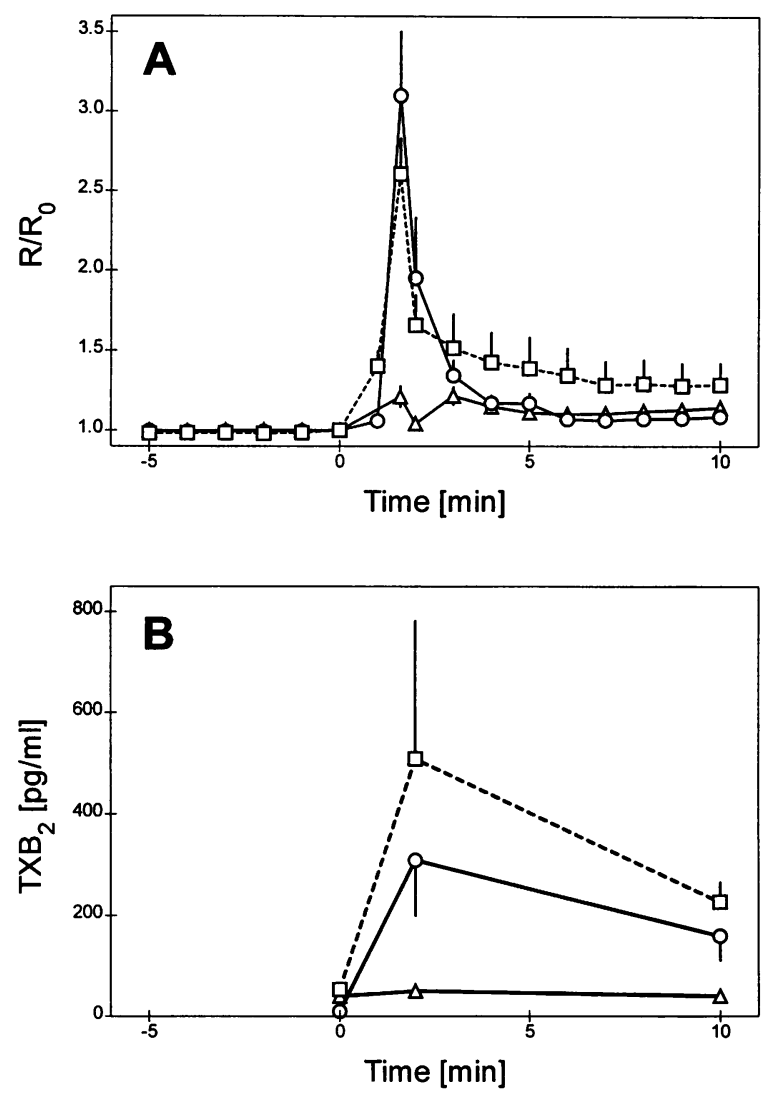

FIG. 7. Time course of 5 nmol PAF-induced bronchoconstriction (A) and TX release (B)

Ten minutes before administration of PAF, lungs were pretreated with $275 \mu \mathrm{M}$ acetyl salicylic acid $(\triangle$; $n=3)$ or $1 \mu \mathrm{M}$ CGP28238 (O; $n=3$; given also 30 min before PAF). Five nanomoles PAF ( $\square$; Panel A: $n=8$, Panel B: $n=3$ ). Data are means \pm SEM. $\mathrm{R} / \mathrm{R}_{\mathrm{O}}$, resistance normalized to time point 0 .

lular source of pulmonary TX is still unclear. Nevertheless, it is of pathophysiological relevance since within the first 24 hours after severe trauma, arterial blood of patients contained more TX than venous blood (26) suggesting increased pulmonary TX production under these conditions. Since the LPS-responses in our system were obtained in the absence of blood-derived leukocytes (2), we exclude these cells as a source of TX. This is in accordance with previous findings that LPS-induced TX formation is reduced neither in thrombopenic sheep (27) nor in neutropenic rats (21). Alveolar macrophages take up LPS as soon as $1 \mathrm{hr}$ after i.p. injection of LPS (28) and human pulmonary TX synthase was demonstrated mainly in mononuclear cells (25). These facts might explain why we found that mRNA for TX synthase was more abundant in alveolar mac-

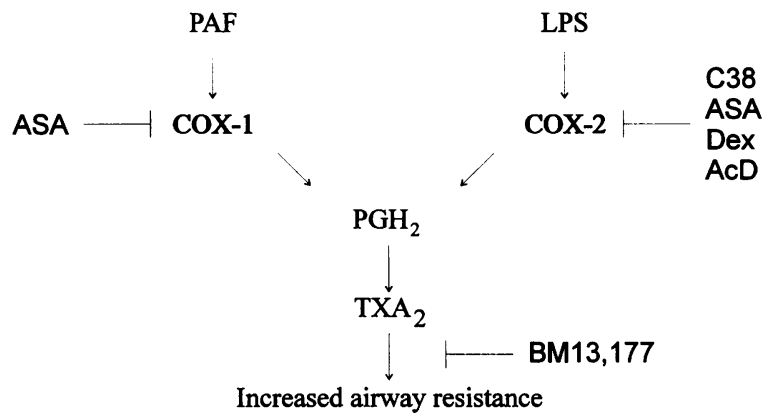

FIG. 8. Proposed mechanism of LPS and PAFinduced bronchoconstriction

Acetyl salicylic acid (ASA) and CGP28238 (C38) inhibit COX; dexamethasone (Dex) and actinomycin D (AcD) prevent induction of COX-2 mRNA.

rophages than in lung tissue. However, COX-2 mRNA amounts induced by LPS were greater in lung tissue than in alveolar macrophages. Because neither LPS nor PAF could elicit TX formation in alveolar macrophages or in isolated pneumocytes in vitro (29) and because in lung slices LPS also failed to induce TX release (30), we can only conclude that LPS-induced TX release requires an intact lung structure.

\section{The Contribution of COX-1 and COX-2 to Bronchoconstriction}

Our interpretation of the results in this study is summarized in Fig. 8. Both PAF and LPS caused release of TX leading to bronchoconstriction. Inhibition of cyclooxygenase with acetyl salicylic acid or TX receptor antagonism prevented the bronchoconstriction in both instances (this study and Ref. 16). Thus, TX-mediated bronchoconstriction appears to be a final common pathway in PAF and LPS-exposed lungs. The time course of this response, however, is markedly different ( $2 \mathrm{~min}$ in response to PAF and about $60 \mathrm{~min}$ in response to LPS). These differences and the failure of PAF receptor antagonism to prevent bronchoconstriction in LPS-treated lungs indicate that separate mechanisms are responsible for TX release in these two models. This view is strongly supported by the differential effects of the COX-2 inhibitor CGP-28238, which prevented the LPSinduced TX release and bronchoconstriction, but was completely ineffective when TX was elicited by PAF. From these facts we conclude that PAF initiates $\mathrm{PGH}_{2}$ supply for TX synthase via cyclooxygenase 1 , whereas upon LPS stimulation this substrate is provided by cyclooxygenase- 2 . 


\section{ACKNOWLEDGMENTS}

This work was supported by the Deutsche Forschungsgemeinschaft, SFB 156, Grant We 686/ 15-1 within the Sonderforschungsbereich 156.

\section{REFERENCES}

1. Murray JF, Matthay MA, Luce JM, Flick MR. (1988) An expanded definiton of the adult respiratory distress syndrome. Am. Rev. Respir. Dis. 138: 720-723.

2. Uhlig S, Brasch F, Wollin L, Fehrenbach $\mathrm{H}$, Richter J, Wendel A. (1995) Functional and fine structural changes in isolated rat lungs challenged with endotoxin ex vivo and in vitro. Am. J. Pathol. 146: 1235-1247.

3. Brigham KL, Meyrick B. (1986) Endotoxin and lung injury. Am. Rev. Respir. Dis. 133: 913-927.

4. Forsgren P, Modig J. (1986) Lung mechanics with relation to pulmonary haemodynamics, gas exchange and extravascular lung water in mechanically ventilated endotoxaemic pigs. Acta Chir. Scand. 152: 561-568.

5. Hardie EM, Olson NC. (1987) Prostaglandin and thromboxane levels during endotoxininduced respiratory failure in pigs. Prostagland. Leukotr. Med. 28: 255-265.

6. DeWitt DL, Meade EA, Smith WL. (1993) PGH synthase isoenzyme selectivity: The potential for safer nonsteroidal anti-inflammatory drugs. Am. J. Med. 95: 40-44.

7. O'Sullivan MG, Huggins EM, Meade EA, Dewitt DL, McCall CE. (1992) Lipopolysaccharide induces prostaglandin- $\mathrm{H}$ synthase- 2 in alveolar macrophages. Biochem. Biophys. Res. Commun. 187: 1123-1127.

8. Hempel SL, Monick MM, Hunninghake GW. (1994) Lipopolysaccharide induces prostaglandin $\mathrm{H}$ synthase- 2 protein and mRNA in human alveolar macrophages and blood monocytes. J. Clin. Invest. 93: 391-396.

9. Mitchell JA, Belvisi MG, Akraeasereenont $P$, et al. (1994) Induction of cyclooxygenase-2 in human pulmonary epithelial cells: Regulation by dexamethasone. Br. J. Pharmacol. 113: $1008-1014$.

10. Chida M, Westcott JY, Voelkel NF. (1994) Dexamethasone and a Ca-antagonist fail to suppress lung cyclooxygenase (COX-2) gene expression in endotoxin primed rats. Am. J Respir. Crit. Care Med. 149: A429.

11. Uhlig S, Wollin L. (1994) An improved set-up for the isolated perfused rat lung. $J$. Pharmacol. Toxicol. Methods 31: 85-94.

12. Bahrami S, Redl H, Leichtfried G, Yu Y, Schlag G. (1994) Similar cytokine but different coagulation responses to lipopolysaccharide injection in $D$-galactosamine-sensitized versus nonsensitized rats. Infect Immun. 62: 99-105.

13. Chang SW. (1992) Endotoxin-induced lung vascular injury-Role of platelet activating factor, tumor necrosis factor and neutrophils. Clin. Res. 40: 528-536.

14. Sprague RS, Stephenson AH, Dahms TE, Lonigro AJ. (1989) Proposed role for leukotrienes in the pathophysiology of multiple systems organ failure. Crit. Care Clin. 5: 315329.

15. Jones TR, Zamboni R, Belley $M$, et al. (1989) Pharmacology of L-660,711 (MK-571): A novel and selective leukotriene $\mathrm{D}_{4}$ receptor antagonist. Can. J Physiol. Pharmacol. 67: 1728.

16. Uhlig S, Wollin L, Wendel A. (1994) Contributions of thromboxane and leukotrienes to platelet-activating factor-induced impairment of lung function in the rat. J. Appl. Physiol. 77: 262-269.

17. Ball HA, Parratt JR, Zeitlin IJ. (1983) Effect of dazoxiben, a specific inhibitor of thromboxane synthetase, on acute pulmonary responses to $E$. coli endotoxin in anaesthetized cats. Br. J. Clin. Pharmacol. 15: 127S-131S.

18. Klein T, Nüsing RM, Pfeilschifter J, Ullrich V. (1994) Selective inhibition of cyclooxygenase 2. Biochem. Pharmacol. 48: 1605-1610.

19. Masferrer JL, Seibert K, Zweifel B. (1992) Endogenous glucocorticoids regulate an inducible cyclooxygenase enzyme. Proc. Natl. Acad. Sci. U.S.A. 89: 3917-3921.

20. Hong SC, Levine L. (1976) Inhibition of arachidonic acid release as the biochemical action of anti-inflammatory steroids. Proc. Natl. Acad. Sci. U.S.A. 73: 1730-1734.

21. Chang SW, Westcott JY, Pickett WC, Murphy RC, Voelkel NF. (1989) Endotoxin-induced lung injury in rats: role of eicosanoids. J. Appl. Physiol. 66: 2409-24l8.

22. Barnard JW, Ward RA, Adkins WK, Taylor AE. (1992) Characterization of thromboxane and prostacyclin effects on pulmonary vascular resistance. J. Appl. Physiol. 72: 1845-1853.

23. Evett GE, Xie W, Chipman JG, Robertson DL, Simmons DL. (1993) Prostaglandin G/H synthase isoenzyme 2 expression in fibro- 
blasts: Regulation by dexamethasone, mitogens, and oncogenes. Arch. Biochem. Biophys. 306: 169-177.

24. Carpenter LJ, Roth RA. (1987) Involvement of thromboxane in injury to isolated rat lungs perfused with phorbol myristate acetate in the presence and absence of neutrophils. Toxicol. Appl. Pharmacol. 91: 33-45.

25. Nüsing R, Ullrich V. (1990) Immunoquantitation of thromboxane synthase in human tissues. Eicosanoids 3: 175-180.

26. Oettinger W, Mayo K, Stager MA, Fischer N, Engst U, Hansen ST. (1989) Thromboxane $\mathrm{A}_{2}$ and granulocyte elastase after severe trauma-Relationship to complications and survival rates. Wien. Klin. Wochenschr. 101: 805-813.

27. Snapper JR, Hinson JM, Hutchinson AA, Lefferts PL, Ogletree ML, Brigham KL.

Contributed by K. F. Austen on February 27, 1996.
(1984) Effects of platelet depletion on the unanaesthetized sheep's pulmonary response to endotoxemia. J. Clin. Invest. 74: 1782-1791.

28. Freudenberg N, Freudenberg MA, Guzman J, Mittermayer C, Bandara K, Galanos C. (1984) Identification of endotoxin-positive cells in the rat lung during shock. Virchows Arch. [A] 404: 197-211.

29. Uhlig S, Wendel A. (1995) Lipid mediators in perfused rat lung. In: von Wichert $P$, Siegenthaler W (eds). Interdisziplinäre Aspekte der Pneumologie. Georg Thieme Verlag, Stuttgart, pp. 66-74.

30. Feuerstein N, Ramwell PW. (1981) In vivo and in vitro effects of endotoxin on prostaglandin release from rat lung. Br. J. Pharmacol. 73: 511-516. 